\title{
Predictive Factors of Pancreatic Fistula After Pancreaticoduodenectomy and External Validation of Predictive Scores
}

\author{
MARCELLO DI MARTINO ${ }^{1,2}$, ISMAEL MORA-GUZMAN ${ }^{3}$, YAGO GARCÍA BLANCO-TRABA ${ }^{3}$, \\ MIGUEL CANTALEJO DÍAZ ${ }^{3}$, MUHAMMAD ARSLAN KHURRAM ${ }^{2}$ and ELENA MARTÍN-PÉREZ ${ }^{1}$ \\ ${ }^{1}$ Department of Surgery, HPB Unit, La Princesa University Hospital, Madrid, Spain; \\ ${ }^{2}$ HPB and Liver Transplant Surgery, Royal Free Hospital, London, U.K.; \\ ${ }^{3}$ Department of Surgery, La Princesa University Hospital, Madrid, Spain
}

\begin{abstract}
Background/Aim: The Fistula Risk Score (FRS), as other risk scores, is a validated model predicting the development of a clinically relevant post-operative pancreatic fistula (CR-POPF) after pancreaticoduodenectomy (PD). We evaluated risk factors related with CR-POPF and correlated four predictive scores with the likelihood of developing CR-POPF in our cohort. Patients and Methods: The records of 107 patients who underwent PD from 2007 to 2015 were obtained from a prospectively maintained database and reviewed. CR-POPFs were categorized by the International Study Group of Pancreatic Fistula (ISGPF) standards. Firstly, a univariate and multivariate analysis of risk factors related to CR-PPOPF was performed, and then the data were correlated with FRS, Wellner's, Robert's and Yamamoto's scores. Results: In total, 30 patients developed a CR-POPF. On multivariate analysis, abdominal thickness $(O R=1.02, p=0.010)$, Wirsung's duct diameter $(O R=0.57$, $p=0.029)$, pancreatic consistency $(O R=3.18, p=0.011)$ and histological diagnosis of the lesion $(O R=1.65, p=0.012)$ represented independent predictive factors of CR-POPF. FRS $\left(R^{2}=0.596, p=0.001\right)$, Wellner's score $\left(R^{2}=0.285, p=0.005\right)$ and Roberts' score $\left(R^{2}=0.385, p=0.002\right)$ correlated with the likelihood of developing CR-POPF. Conclusion: Abdominal thickness, Wirsung's duct diameter, pancreatic consistency and histological diagnosis were independent predictive factors of $C R$ $P O P F$. Predictive scores reflected the likelihood of $C R-P O P F$, FRS being the score with the highest predictive value.
\end{abstract}

Article presented as oral presentation at XXXI Spanish National Congress, Madrid, November 2016.

Correspondence to: Marcello Di Martino, c/Diego de Leon 62, 28006, Madrid, Spain. Tel: +34 654583554, e-mail: marcellodima@gmail.com

Key Words: Pancreatic fistula, pancreaticoduodenectomy, pancreatic surgery, pancreatic ductal adenocarcinoma, predictive scores.
Pancreaticoduodenectomy (PD) remains the surgical procedure of choice for the vast majority of the head of pancreas lesions. Despite the reduction in mortality to $1-5 \%$, post-operative morbidity remains significant at 30-50\% (1-4), pancreatic fistula (PF) being the real Achilles heel of this technique (5-7). The International Study Group of Pancreatic Fistula (ISGPF) recently updated the definition and grading of postoperative pancreatic fistula, that had previously classified $\mathrm{PF}$ into three categories $(8,9)$. The previous type $\mathrm{A}$ is now considered as a biochemical leak and types $\mathrm{B}$ and $\mathrm{C}$ are classified as clinically relevant post-operative PF (CR-POPF).

The rate of CR-POPF has been correlated to several factors on multivariate analysis, including, body mass index (BMI), sex, age, neoadjuvant treatment, histological diagnosis of tumour, pancreatic consistency, Wirsung's duct diameter, as well as the type of pancreatic anastomosis or the use of external drain (10-17).

So far, there has not been an ideal strategy to nullify the risk of CR-POPF, however based on these factors, a number of groups have proposed predictive scores to stratify the risk of developing CR-POPF. These scores, if reliable, could represent a useful tool in order to improve the management of patients undergoing PD.

The aim of the present study was to evaluate the risk factors related to the development of CR-POPF and correlate predictive scores.

\section{Patients and Methods}

A retrospective analysis was undertaken to identify all consecutive PDs performed at the La Princesa University Hospital from 2007 to 2015.

Preoperative assessment included a staging computed tomography (CT). The size of pancreatic duct and the intrabdominal thickness were retrospectively reviewed; the latter being defined as the distance from the posterior surface of the rectus abdominis to the aortic back wall at the level of the umbilicus. The main pancreatic 


\begin{tabular}{lcc}
\multicolumn{2}{l}{ A: Fistula Risk Score. Adapted from (10) } \\
\hline \multirow{2}{*}{ Risk factor } & Parameter & Points* \\
Gland texture & & 0 \\
\hline Pathology & Firm & 2 \\
\cline { 2 - 3 } & Soft & 0 \\
Pancreatic duct diameter, & Pancreatic adenocarcinoma or \\
mm & $=5$ & 1 \\
\cline { 2 - 3 } & 4 & 0 \\
\cline { 2 - 3 } & 3 & 1 \\
\cline { 2 - 3 } & 2 & 2 \\
\hline Intraoperative blood loss, & $=1$ & 3 \\
mL & 400 & 0 \\
& $401-700$ & 1 \\
& $701-1,000$ & 2 \\
*Total 0 to 10 points & 1,000 & 3
\end{tabular}

\begin{tabular}{l} 
C: Roberts' score. Adapted from (17) \\
$\frac{\text { Factors }}{\exp (-3.206+0.107[\mathrm{BMI}]-0.404[\text { pancreatic ductwidth mm]) }}$ \\
$1+\{\exp (-3.206+0.107[\mathrm{BMI}]-0.404[$ pancreatic ductwidth mm])\} \\
\hline
\end{tabular}

B: Wellner's score. Adapted from (11)

\begin{tabular}{lc}
\hline \multicolumn{1}{c}{ Factor } & Value $^{*}$ \\
& +1 \\
\hline Age $>66$ years & +1 \\
\hline Preoperative diagnosis other than pancreatic carcinoma or chronic pancreatitis & -1 \\
History of smoking & -1 \\
History of weight loss & -1
\end{tabular}

Value -3 to +2 points

\begin{tabular}{lcc} 
D: Yamamoto's score. Adapted from (13) & \\
\hline Risk factor & Parameter & Points* \\
MPD index & $<0.25$ & $\mathbf{2}$ \\
\hline Relation to portal vein on CT & $=0.25$ & 0 \\
\cline { 2 - 3 } & Involved portal vein & 0 \\
Gander & Away from portal vein & 2 \\
Intra-abdominal fat thickness & Male & 1 \\
& Female & 0 \\
& $=65 \mathrm{~mm}$ & 0 \\
\hline Diagnosis & $>65 \mathrm{~mm}$ & 1 \\
\hline *Total 0 to 7 points & Pancreatic cancer & 0 \\
\cline { 2 - 3 } & Disease other than pancreatic \\
\hline
\end{tabular}

MPD: main pancreatic duct

Figure 1. Resume of prognostic scores: A: Fistula Risk Score (10); B: Wellner's Score (11); C: Robert's Score (17); D: Yamamoto's Score (13).

duct (MPD) index was defined as the ratio of the diameter of MPD to the diameter of the short axis of the pancreatic body.

The surgical team was composed of surgeons experienced in pancreatic surgery who did not change over the study period. Classic Whipple was the standard surgical procedure. Tumours involving superior mesenteric vein (SMV) or portal vein (PV) were treated by en-bloc resection of the vein. Pancreas consistency was assessed intraoperatively. The anastomotic technique employed was a pancreticojejunostomy, either duct to mucosa in two layers or a dunking pancreticojejunostomy. Two intraoperative drains were placed at the end of the procedure and somatostatin analogues were used in all patients. Postoperative antibiotics and total parenteral nutrition were used in case of infection or delayed gastric emptying.

The incidence of pancreatic fistula was assessed following the ISGPF classification (8). Biochemical fistulas (Grade A) were characterized by elevated drain amylase ( $>3$ times the upper limit of serum amylase concentration on post-operative day 3 ). Clinically relevant pancreatic fistulas (CR-POPF) included Grade B and C. All patients managed using antibiotic therapy, supplemental nutrition (total parenteral nutrition), transfusion, continued drainage for more than 3 weeks or additional percutaneous drains were considered as Grade B PF. Grade C PF included patients requiring operative intervention under general anaesthesia.

Four pancreatic scores were analysed; Callery's score (10), also known as Fistula Risk Score (FRS) (Figure 1A), Wellner's score (11) (Figure 1B), Yamamoto's score (13) (Figure 1C) and Roberts's score $(12,17)$ (Figure 1D). Each risk factor was associated with discrete numerical values as described by the different predictive scores. The weighted aggregate of these risk factors was used to calculate individual fistula risk score (from 0 to 10 in FRS; from 2 to +3 in Wellner's score; from 0 to 7 in Yamamoto's score and as discrete variable in Roberts' score).
All statistical analyses were performed using SPSS ${ }^{\circledR} 21.0$ for Windows (SPSS, Chicago, IL, USA). Descriptive values are expressed as percentage or mean \pm standard deviation (SD) and median with interquartile range. Fisher's exact test was used for comparison of categorical variables and the Student's $t$-test was used for continuous variables. For the multivariate analysis, only parameters with a $p$-value $<0.01$ in the univariate model were entered in the Cox regression model. Coefficient of determination (R2) was used to assess the reliability of pancreatic scores. The differences were considered significant at $p$-value $<0.05$.

\section{Results}

The study included 107 patients, as shown in Table I. Mean age was $66.3 \pm 9.7$ years; 67 patients $(62.6 \%)$ were male, mean BMI was $25.9( \pm 4.3)$. Venous infiltration was detected on preoperative CT in 19 cases $(17.7 \%)$, Wirsung's duct diameter was $3.6 \mathrm{~mm}( \pm 1.7)$ and abdominal thickness was $136.5 \mathrm{~mm}( \pm 31.4)$. Pancreas was soft in 42 cases $(39.3 \%)$, the anastomosis was an end to side, duct to mucosa, in 89 patients $(83.1 \%)$. The majority of resected lesions originated from the pancreas. Thirty patients $(28.0 \%)$ presented a CRPOPF, 20 (18.7\%) being PF type B and 10 (9.3\%) PF type C.

On univariate analysis, smaller Wirsung's duct diameter $(2.8 \pm 1.0 \mathrm{~mm}$ vs. $4.0 \pm 1.7 \mathrm{~mm}, p=0.001)$; a wider abdominal thickness $(145.7 \pm 31.6 \mathrm{~mm} v s .130 .1 \pm 29.1 \mathrm{~mm}, p=0.012)$; softer pancreas $(83.1 \%$ vs. $17.0 \%, p=0.001)$; no vascular resection (5.3\% vs. 94.7\%, $p=0.021$ ); dunking pancreaticojejunostomy (22.4\% vs. $77.5 \%, p=0.009)$ and a lower percentage of 
Table I. Univariate analysis.

\begin{tabular}{|c|c|c|c|c|}
\hline $\begin{array}{l}\text { Variable } \\
\mathrm{N}\end{array}$ & $\begin{array}{c}\text { Total } \\
107\end{array}$ & $\begin{array}{c}\text { No CR-POPF } \\
77(72.0 \%)\end{array}$ & $\begin{array}{c}\text { CR-POPF } \\
30(28.0 \%)\end{array}$ & $p$-Value \\
\hline \multicolumn{5}{|l|}{ Demographic variable } \\
\hline Age (mean, SD) & $66.3( \pm 9.7)$ & $66.5( \pm 10.4)$ & $65.8( \pm 11.7)$ & 0.767 \\
\hline Gender (male) (n, \%) & $67(62.6 \%)$ & $47(70.1 \%)$ & $20(29.9 \%)$ & 0.660 \\
\hline BMI (mean, SD) & $25.9( \pm 4.3)$ & $25.5( \pm 4.3)$ & $27.1( \pm 3.9)$ & 0.171 \\
\hline Smoker (n, \%) & $40(37.4 \%)$ & $30(75.0 \%)$ & $10(25.0 \%)$ & 0.660 \\
\hline Drinker $(\mathrm{n}, \%)$ & $22(20.6 \%)$ & $18(81.8 \%)$ & $4(18.2 \%)$ & 0.298 \\
\hline Previous pancreatitis $(\mathrm{n}, \%)$ & $8(7.5 \%)$ & $6(75.0 \%)$ & $2(25.0 \%)$ & 0.238 \\
\hline $\operatorname{ASA}(\mathrm{n}, \%)$ & & & & 0.394 \\
\hline I & $6(5.6 \%)$ & $4(66.7 \%)$ & $2(33.3 \%)$ & \\
\hline II & $56(52.3 \%)$ & $42(75.0 \%)$ & $13(23.2 \%)$ & \\
\hline III & $45(42.1 \%)$ & $30(66.7 \%)$ & $15(33.3 \%)$ & \\
\hline \multicolumn{5}{|l|}{ Signs and symptoms } \\
\hline Weight lost $>5 \mathrm{~kg}(\mathrm{n}, \%)$ & $34(31.8 \%)$ & $25(73.5 \%)$ & $9(26.5 \%)$ & 1.000 \\
\hline \multicolumn{5}{|l|}{ CT findings } \\
\hline Size of lesion (mean, SD) & $2.9( \pm 1.5)$ & $2.8( \pm 1.5)$ & $3.1( \pm 1.5)$ & 0.631 \\
\hline Venous infiltration $(\mathrm{n}, \%)$ & $19(17.7 \%)$ & $16(84.2 \%)$ & $3(15.7 \%)$ & 0.089 \\
\hline Wirsung's diameter (mm) (mean, SD) & $3.6( \pm 1.7)$ & $4.0( \pm 1.8)$ & $2.8( \pm 1.0)$ & 0.001 \\
\hline Abdominal thickness (mm) (mean, SD) & $136.5( \pm 31.4)$ & $130.1( \pm 29.1)$ & $145.7( \pm 31.6)$ & 0.012 \\
\hline \multicolumn{5}{|l|}{ Other preoperative variables } \\
\hline Preoperative drain $(\mathrm{n}, \%)$ & $73(68.2 \%)$ & $52(71.2 \%)$ & $21(28.8 \%)$ & 1.000 \\
\hline Neoadjuvant treatment $(\mathrm{n}, \%)$ & $4(3.6 \%)$ & $3(75.0 \%)$ & $1(25.0 \%)$ & 0.639 \\
\hline \multicolumn{5}{|l|}{ Surgery } \\
\hline Pancreas consistency (n, \%) & & & & 0.001 \\
\hline Hard & $65(60.7 \%)$ & $54(83.1 \%)$ & $11(17.0 \%)$ & \\
\hline Soft & $42(39.3 \%)$ & $18(42.8 \%)$ & $24(57.1 \%)$ & \\
\hline Vascular resection (n, \%) & $19(17.3 \%)$ & $18(94.7 \%)$ & $1(5.3 \%)$ & 0.021 \\
\hline Anastomosis $(\mathrm{n}, \%)$ & & & & 0.009 \\
\hline D-M PJ & $89(83.1 \%)$ & $69(77.5 \%)$ & $20(22.4 \%)$ & \\
\hline Dunking PJ & $18(16.8 \%)$ & $8(44.4 \%)$ & $10(55.6 \%)$ & \\
\hline Blood lost (27) (mean, SD) & $418( \pm 320)$ & $405( \pm 323)$ & $449( \pm 317)$ & 0.580 \\
\hline Surgical time (min) (mean, SD) & $448( \pm 93)$ & $456( \pm 97)$ & $429( \pm 81)$ & 0.202 \\
\hline \multicolumn{5}{|l|}{ Histopathology } \\
\hline Origin $(\mathrm{n}, \%)$ & & & & 0.008 \\
\hline Pancreas & $60(56.1 \%)$ & $51(85.0 \%)$ & $9(15.0 \%)$ & \\
\hline Bile duct & $11(10.1 \%)$ & $5(45.4 \%)$ & $6(55.5 \%)$ & \\
\hline Duodenum & $5(4.7 \%)$ & $2(40.0 \%)$ & $3(60.0 \%)$ & \\
\hline Vater's tumour & $21(19.1 \%)$ & $12(57.1 \%)$ & $9(42.9 \%)$ & \\
\hline \multicolumn{5}{|l|}{ Postoperative } \\
\hline Fistulas (n, \%) & $61(57.0 \%)$ & & & \\
\hline Type A & $16(15.0 \%)$ & & & \\
\hline Type B & $20(18.7 \%)$ & & & \\
\hline Type C & $10(9.3 \%)$ & & & \\
\hline
\end{tabular}

BMI: Body mass index; ASA: American Society of Anesthesiologists Classification; CT: computed tomography; D-M PJ: duct-to-mucosa pancreaticojejunostomoy; PJ: pancreaticojejunostomy; SD: standard deviation.

pancreatic lesions $(p=0.008)$ (Table II) were found to be risk factors of CR-POPF.

On multivariate analysis, abdominal thickness $(\mathrm{OR}=1.02$, $p=0.010)$, Wirsung's duct diameter ( $\mathrm{OR}=0.57, p=0.029)$, pancreatic consistency $(\mathrm{OR}=3.18, p=0.011)$ and histologic diagnosis of the lesion $(\mathrm{OR}=1.65, p=0.012)$ represented independent predictive factors of CR-POPF (Table III).
The correlation analysis between the predictive scores and the likelihood of developing CR-POPF in our cohort showed a significant association with FRS $\left(\mathrm{R}^{2}=0.596\right.$, $p=0.001)$ (Figure 2A), Wellner's score $\left(\mathrm{R}^{2}=0.285, p=0.005\right)$ (Figure 2B) and Roberts' score $\left(\mathrm{R}^{2}=0.385, p=0.002\right)$. There was no significant correlation with Yamamoto's score (Figure 2C). 
Table II. Multivariate analysis.

\begin{tabular}{lccc}
\hline Variable & OR & $95 \% \mathrm{CI}$ & $p$-Value \\
\hline Abdominal thickness & 1.02 & $1.01-1.05$ & 0.010 \\
Wirsung' diameter & 0.57 & $0.34-0.94$ & 0.029 \\
Pancreas' consistency & 3.18 & $1.38-7.74$ & 0.011 \\
Vascular resection & & & 0.279 \\
Pancreatic anastomosis & & & 0.058 \\
Histologic type & 1.65 & $1.12-2.44$ & 0.012 \\
\hline
\end{tabular}

OR: Odd ratio; 95\%CI: 95\% Confidence interval.

Table III. Correlation analysis.

\begin{tabular}{lcc}
\hline Variable & $\mathrm{R}^{2}$ & $p$-Value \\
\hline Callery's Score & 0.596 & 0.001 \\
Wellner's Score & 0.285 & 0.005 \\
Roberts' Score & 0.350 & 0.002 \\
Yamamoto's Score & -- & 0.244 \\
\hline
\end{tabular}

$\mathrm{R}^{2}$ : Coefficient of determination.

\section{Discussion}

Pancreatic fistula remains the Achilles heels of PD. Despite a consensus definition of $\mathrm{PF}(8,9)$ and recent improvements in the surgical technique, the incidence of clinically relevant fistula has remained constant, between $13-36 \%(1,7,10,18)$. Several groups have proposed different predictive scores of $\mathrm{PF}$, based either on preoperative or both preoperative and intraoperative parameters. This series outlines that predictive factors like abdominal thickness, Wirsung's duct diameter, pancreatic consistency and histologic diagnosis of the lesion are related with an increase in the rate of CR-POPF. Furthermore, FRS, Wellner's score and Robert's score represented valid tools to assess the risk of CR-POPF. It is important to consider the magnitude of the correlation as well as the variables included in each score. While FRS takes into account both preoperative and intraoperative findings, the other two scores consider only preoperative variables. FRS was our preferred predictive score as it showed the strongest correlation with our series and at the same time it took into account Wirsung's duct diameter, pancreatic consistency and histologic diagnosis, which were independent predictive factors of CP-POPF in our multivariate analysis.

Patients with a higher predictive score should be offered the best available tools and strategy in order to minimize the risk of a CR-POPF. Several meta-analyses (19-23) have shown some advantages of pancreaticogastrostomy in reducing the incidence of pancreatic fistula. Although a reduction in mortality has never been clearly proven, the reduction of CR-
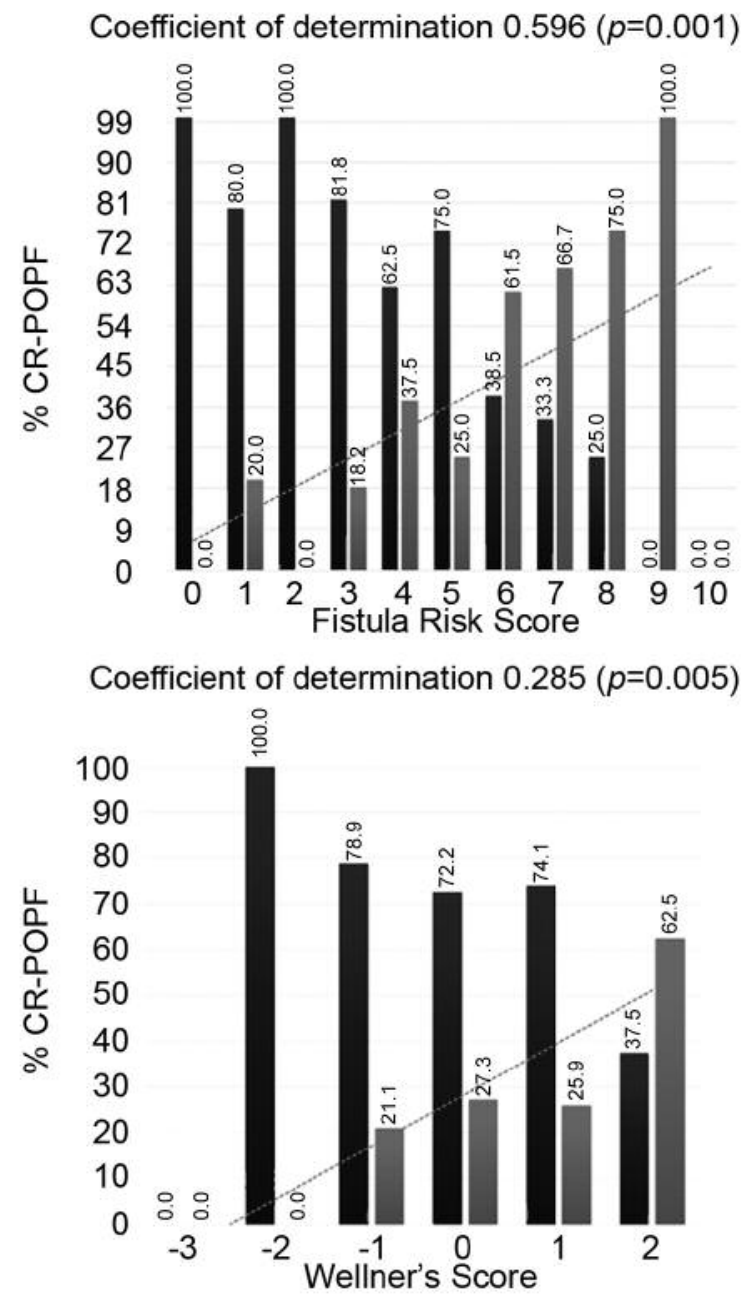

Coefficient of determination 0. NS $(p=0.244)$

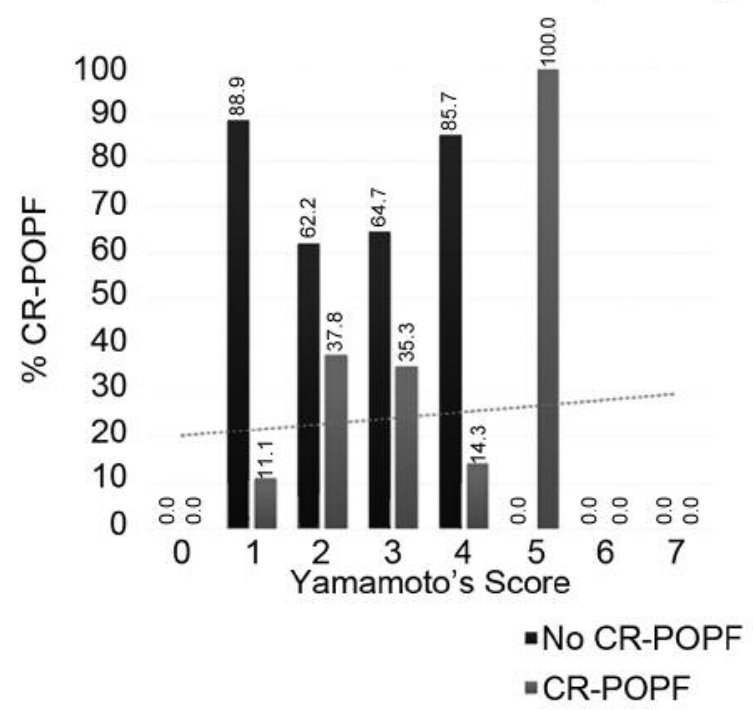

Figure 2. Correlation analysis showing the likelihood of developing CR-POPF. A: Fistula Risk Score (10); B: Wellner's Score (11); C: Yamamoto's Score (13). 
POPF could help to reduce morbidity in high-risk patients. As an alternative strategy, Pessaux et al. (18) proposed the use of an external pancreatic drain in order to reduce the incidence of CR-POPF. Their prospective multicentre randomized clinical trial showed a decrease in PFs from 42-26\%, $p=0.034$. Similar results have also been confirmed by Motoi et al. (24), highlighting that an external pancreatic drain could represent a useful tool, especially in patients with high predictive fistula scores. In addition to this, somatostatin analogues have shown contradictory results $(25,26)$, but Allen et al. (27) recently showed a significant decrease in CR-POPF from $21-10 \%$ $(p=0.006)$ in patients treated with pasireotide, which could represent an effective tool when the likelihood of CR-POPF is high. The stratification of pancreatic fistula risk based on predictive scores is a fundamental tool in order to personalize surgical and postoperative strategies, keeping in mind all of the above strategies to reduce the incidence of CR-POPF in high-risk patients.

On the other hand, patients with lower predictive scores could be selected for not having an abdominal drain and for early feeding. A recent multicentric prospective trial by McMillan et al. (28) advised to omit the use of abdominal drain in low-risk patients and stratify the removal of abdominal drain in high- and intermediate-risk patients, based on postoperative drain fluid amylase. A recent prospective analysis by Bertens et al. (29) compared the value of drain fluid amylase (DFA) on postoperative day 1 to the FRS, highlighting both as predictors of CR-POPF. Therefore, FRS and DFA can be used as independent indicators of early drain removal.

Risk stratification of CR-POPF may have a role in selecting patients appropriate for training and evaluate surgical results. Pancreatic anastomosis is classically considered as one of the most challenging steps for both trainers to teach and trainees to learn (14). A stratification of PF risk could allow trainees to perform less risky anastomoses and at the same time establish surgical performance more accurately. In order to continue to progress and improve, outcomes after PD should be routinely stratified by risk categories based on predictive scores. These scores should become a quality control by which all PDs are evaluated. This will unify the reporting of PFs across institutions and hence make future comparisons more meaningful (30).

Our results demonstrated a correlation between CR-POPF and predictive pancreatic fistula scores, FRS being the one with the highest predictive value in our series. However, our study, presents certain limitations including the retrospective nature of analysis and the limited number of cases. Furthermore, other pancreatic fistula scores (31-33) were not analysed due to the lack of specific data related to score's variables. The routine utilization of these scores could help improve the perioperative management of patients undergoing PD, but a larger series based on multicentric studies could better compare and assess the value of different predictive scores.

\section{Conclusion}

Predictive factors like abdominal thickness, Wirsung's duct diameter, pancreatic consistency and histological diagnosis of the lesion are independent predicative factors of CRPOPF. Furthermore, a correlation between CR-POPF and predictive pancreatic fistula scores was found, FRS providing the highest predictive value. Personalizing the management of each case based on reliable predictive fistula scores could reduce severe complications related with CRPOPF, and promote an enhanced recovery.

\section{References}

1 Winter JM, Cameron JL, Campbell KA, Arnold MA, Chang DC, Coleman J, Hodgin MB, Sauter PK, Hruban RH, Riall TS, Schulick RD, Choti MA, Lillemoe KD and Yeo CJ: 1423 pancreaticoduodenectomies for pancreatic cancer: A singleinstitution experience. J Gastrointest Surg 10: 1199-1210, 2006.

2 Ho CK, Kleeff J, Friess H and Buchler MW: Complications of pancreatic surgery. HPB (Oxford) 7: 99-108, 2005.

3 McMillan MT, Allegrini V, Asbun HJ, Ball CG, Bassi C, Beane JD, Behrman SW, Berger AC, Bloomston M, Callery MP, Christein JD, Dickson E, Dixon E, Drebin JA, Fernandez-Del Castillo C, Fisher WE, Fong ZV, Haverick E, Hollis RH, House MG, Hughes SJ, Jamieson NB, Kent TS, Kowalsky SJ, Kunstman JW, Malleo G, McElhany AL, Salem RR, Soares KC, Sprys MH, Valero V, 3rd, Watkins AA, Wolfgang CL, Zureikat $\mathrm{AH}$ and Vollmer CM Jr.: Incorporation of procedure-specific risk into the ACS-NSQIP surgical risk calculator improves the prediction of morbidity and mortality after pancreatoduodenectomy. Ann Surg 265: 978-986, 2017.

4 Pedrazzoli S: Pancreatoduodenectomy (PD) and postoperative pancreatic fistula (POPF): A systematic review and analysis of the POPF-related mortality rate in 60,739 patients retrieved from the English literature published between 1990 and 2015. Medicine (Baltimore) 96: e6858, 2017.

5 Greenblatt DY, Kelly KJ, Rajamanickam V, Wan Y, Hanson T, Rettammel R, Winslow ER, Cho CS and Weber SM: Preoperative factors predict perioperative morbidity and mortality after pancreaticoduodenectomy. Ann Surg Oncol 18: 2126-2135, 2011.

6 Kneuertz PJ, Pitt HA, Bilimoria KY, Smiley JP, Cohen ME, Ko CY and Pawlik TM: Risk of morbidity and mortality following hepatopancreato-biliary surgery. J Gastrointest Surg 16: 1727-1735, 2012.

7 Ecker BL, McMillan MT, Asbun HJ, Ball CG, Bassi C, Beane JD, Behrman SW, Berger AC, Dickson EJ, Bloomston M, Callery MP, Christein JD, Dixon E, Drebin JA, Castillo CF, Fisher WE, Fong ZV, Haverick E, Hollis RH, House MG, Hughes SJ, Jamieson NB, Javed AA, Kent TS, Kowalsky SJ, Kunstman JW, Malleo G, Poruk KE, Salem RR, Schmidt CR, Soares K, Stauffer JA, Valero V, Velu LKP, Watkins AA, Wolfgang CL, Zureikat AH and Vollmer CM Jr.: Characterization and Optimal Management of High-risk Pancreatic Anastomoses During Pancreatoduodenectomy. Ann Surg 267: 608-616, 2018.

8 Bassi C, Marchegiani G, Dervenis C, Sarr M, Abu Hilal M, Adham M, Allen P, Andersson R, Asbun HJ, Besselink MG, Conlon K, Del Chiaro M, Falconi M, Fernandez-Cruz L, Fernandez-Del Castillo C, Fingerhut A, Friess H, Gouma DJ, Hackert T, Izbicki J, Lillemoe KD, Neoptolemos JP, Olah A, Schulick R, Shrikhande 
SV, Takada T, Takaori K, Traverso W, Vollmer CR, Wolfgang CL, Yeo CJ, Salvia R, Buchler M, International Study Group on Pancreatic S. The 2016 update of the International Study Group (ISGPS) definition and grading of postoperative pancreatic fistula: 11 Years After. Surgery 161: 584-591, 2017.

9 Bassi C, Dervenis C, Butturini G, Fingerhut A, Yeo C, Izbicki J, Neoptolemos J, Sarr M, Traverso W, Buchler M and International Study Group on Pancreatic Fistula D: Postoperative pancreatic fistula: an international study group (ISGPF) definition. Surgery 138: 8-13, 2005.

10 Callery MP, Pratt WB, Kent TS, Chaikof EL and Vollmer CM Jr.: A prospectively validated clinical risk score accurately predicts pancreatic fistula after pancreatoduodenectomy. J Am Coll Surg 216: 1-14, 2013.

11 Wellner UF, Kayser G, Lapshyn H, Sick O, Makowiec F, Hoppner J, Hopt UT and Keck T: A simple scoring system based on clinical factors related to pancreatic texture predicts postoperative pancreatic fistula preoperatively. HPB (Oxford) 12: 696-702, 2010.

12 Roberts KJ, Hodson J, Mehrzad H, Marudanayagam R, Sutcliffe RP, Muiesan P, Isaac J, Bramhall SR and Mirza DF: A preoperative predictive score of pancreatic fistula following pancreatoduodenectomy. HPB (Oxford) 16: 620-628, 2014.

13 Yamamoto Y, Sakamoto Y, Nara S, Esaki M, Shimada K and Kosuge T: A preoperative predictive scoring system for postoperative pancreatic fistula after pancreaticoduodenectomy. World J Surg 35: 2747-2755, 2011.

14 Vallance AE, Young AL, Macutkiewicz C, Roberts KJ and Smith AM: Calculating the risk of a pancreatic fistula after a pancreaticoduodenectomy: a systematic review. HPB (Oxford) 17: 1040-1048, 2015.

15 Pratt WB, Callery MP and Vollmer CM Jr.: Risk prediction for development of pancreatic fistula using the ISGPF classification scheme. World J Surg 32: 419-428, 2008.

16 McMillan MT and Vollmer CM Jr.: Predictive factors for pancreatic fistula following pancreatectomy. Langenbecks Arch Surg 399: 811-824, 2014.

17 Roberts KJ, Sutcliffe RP, Marudanayagam R, Hodson J, Isaac J, Muiesan P, Navarro A, Patel K, Jah A, Napetti S, Adair A, Lazaridis S, Prachalias A, Shingler G, Al-Sarireh B, Storey R, Smith AM, Shah N, Fusai G, Ahmed J, Abu Hilal M and Mirza DF: Scoring System to Predict Pancreatic Fistula After Pancreaticoduodenectomy: A UK Multicenter Study. Ann Surg 261: 1191-1197, 2015.

18 Pessaux P, Sauvanet A, Mariette C, Paye F, Muscari F, Cunha AS, Sastre B, Arnaud JP and Federation de Recherche en C: External pancreatic duct stent decreases pancreatic fistula rate after pancreaticoduodenectomy: prospective multicenter randomized trial. Ann Surg 253: 879-885, 2011.

19 Zhang X, Ma L, Gao X, Bao H, Liu P, Aziz A, Wang Z and Gong P: Pancreaticogastrostomy versus pancreaticojejunostomy reconstruction after pancreaticoduodenectomy: a meta-analysis of randomized controlled trials. Surg Today 45: 585-594, 2015.

20 Que W, Fang H, Yan B, Li J, Guo W, Zhai W and Zhang S: Pancreaticogastrostomy versus pancreaticojejunostomy after pancreaticoduodenectomy: a meta-analysis of randomized controlled trials. Am J Surg 209: 1074-1082, 2015.

21 Hallet J, Zih FS, Deobald RG, Scheer AS, Law CH, Coburn NG and Karanicolas PJ: The impact of pancreaticojejunostomy versus pancreaticogastrostomy reconstruction on pancreatic fistula after pancreaticoduodenectomy: meta-analysis of randomized controlled trials. HPB (Oxford) 17: 113-122, 2015.

22 Clerveus M, Morandeira-Rivas A, Picazo-Yeste J and MorenoSanz C: Pancreaticogastrostomy versus pancreaticojejunostomy after pancreaticoduodenectomy: a systematic review and metaanalysis of randomized controlled trials. J Gastrointest Surg 18: 1693-1704, 2014.

23 Cheng Y, Briarava M, Lai M, Wang X, Tu B, Cheng N, Gong J, Yuan Y, Pilati P and Mocellin S: Pancreaticojejunostomy versus pancreaticogastrostomy reconstruction for the prevention of postoperative pancreatic fistula following pancreaticoduodenectomy. Cochrane Database Syst Rev 9: CD012257, 2017.

24 Motoi F, Egawa S, Rikiyama T, Katayose Y and Unno M: Randomized clinical trial of external stent drainage of the pancreatic duct to reduce postoperative pancreatic fistula after pancreaticojejunostomy. Br J Surg 99: 524-531, 2012.

25 Gurusamy KS, Koti R, Fusai G and Davidson BR: Somatostatin analogues for pancreatic surgery. Cochrane Database Syst Rev (4): CD008370, 2012.

26 McMillan MT, Christein JD, Callery MP, Behrman SW, Drebin JA, Kent TS, Miller BC, Lewis RS Jr. and Vollmer CM Jr: Prophylactic octreotide for pancreatoduodenectomy: more harm than good? HPB (Oxford) 16: 954-962, 2014.

27 Allen PJ, Gonen M, Brennan MF, Bucknor AA, Robinson LM, Pappas MM, Carlucci KE, D'Angelica MI, DeMatteo RP, Kingham TP, Fong $\mathrm{Y}$ and Jarnagin WR: Pasireotide for postoperative pancreatic fistula. N Engl J Med 370: 2014-2022, 2014.

28 McMillan MT, Malleo G, Bassi C, Allegrini V, Casetti L, Drebin JA, Esposito A, Landoni L, Lee MK, Pulvirenti A, Roses RE, Salvia R and Vollmer CM Jr.: Multicenter, prospective trial of selective drain management for pancreatoduodenectomy using risk stratification. Ann Surg 265: 1209-1218, 2017.

29 Bertens KA, Crown A, Clanton J, Alemi F, Alseidi AA, Biehl T, Helton WS and Rocha FG: What is a better predictor of clinically relevant postoperative pancreatic fistula (CR-POPF) following pancreaticoduodenectomy (PD): postoperative day one drain amylase (POD1DA) or the fistula risk score (FRS)? HPB (Oxford) 19: 75-81, 2016.

30 Shubert CR, Wagie AE, Farnell MB, Nagorney DM, Que FG, Reid Lombardo KM, Truty MJ, Smoot RL and Kendrick ML: Clinical risk score to predict pancreatic fistula after pancreatoduodenectomy: independent external validation for open and laparoscopic approaches. J Am Coll Surg 221: 689-698, 2015.

31 Graham JA, Kayser R, Smirniotopoulos J, Nusbaum JD and Johnson LB: Probability prediction of a postoperative pancreatic fistula after a pancreaticoduodenectomy allows for more transparency with patients and can facilitate management of expectations. J Surg Oncol 108: 137-138, 2013.

32 Gaujoux S, Cortes A, Couvelard A, Noullet S, Clavel L, Rebours V, Levy P, Sauvanet A, Ruszniewski P and Belghiti J: Fatty pancreas and increased body mass index are risk factors of pancreatic fistula after pancreaticoduodenectomy. Surgery 148: 15-23, 2010.

33 Fujiwara Y, Misawa T, Shiba H, Shirai Y, Iwase R, Haruki K, Furukawa K, Futagawa Y and Yanaga K: A novel postoperative inflammatory score predicts postoperative pancreatic fistula after pancreatic resection. Anticancer Res 33: 5005-5010, 2013.

Received November 20, 2018

Revised December 3, 2018

Accepted December 7, 2018 